\title{
Communication Strategies of Multi-subjects for Micro Public Welfare from the Perspective of Social Network Relationship
}

\author{
Qin Wang ${ }^{1}$ \\ ${ }^{1}$ College of Liberal Arts, Dongguan University of Technology, Dongguan, Guangdong, China \\ Correspondence: Qin Wang, College of Liberal Arts, Dongguan University of Technology, Dongguan, Guangdong, \\ China. E-mail: wangqinjaney@126.com
}

Received: August 23, 2015 Accepted: September 5, 2015 Online Published: October 10, 2015

doi:10.5430/wjss.v3n1p1 URL: http://dx.doi.org/10.5430/wjss.v3n1p1

\begin{abstract}
From the research perspective of social network relationship, this paper analyzes the roles that are respectively played by information bridge node, core node and long tail node. Then, it probes into the fact that media professionals, public welfare organizations and MicroBlog citizen individuals in communities of network public welfare respectively take advantage of the relationship of the social network they are located in and exploit opportunities of new media empowerment to realize group mobilization and resource integration. Especially, the paper focuses on making a thorough inquiry into the communication strategies used by multi-subjects in micro public welfare based on social network relationship.
\end{abstract}

Keywords: social network relationship, communication network of micro public welfare, node, new media empowerment, group mobilization, resource integration, multi-subject, communication strategy

\section{Proposal of Research Questions}

With popularization of application of such socialized media as MicroBlog, the space of public welfare communication guided by the value idea of public welfare of all the people has got largely expanded. As a newly emerging public welfare communication form, micro public welfare has become a routinized citizen practice in exercising the autonomous rights of citizens, embodying the autonomous spirit of citizens and spreading the spirit of public good in a new media era. Compared with the traditional public welfare communication, micro public welfare resorts such socialized media as MicroBlog to launch, popularize and spread on-line public welfare communication and interaction, and, oriented by problems, mobilizes all the people to participate in the public welfare. It triggers discussion of Microblog citizens on the topic of public welfare with the information assembly effect of MicroBlog. Moreover, it follows up a survey on public welfare off-line, launches activities of doing good and evolves from accumulation of "miniature" action by an individual to "colossal" public welfare actions. It connects and mobilizes all possible resources to seek to achieve the purposes of "action changing China", and facilitating the society to develop towards harmony and kind-heartedness. As an incubator of micro public welfare, how does MicroBlog mobilize a group with new media empowerment? How do multi-subjects (media professionals, public welfare organizations and individuals) based on the social network relationship collaborate in promoting micro public welfare communication and establish mutually trustful organizational mechanism? How do the multi-subjects in micro public welfare use the social network relationship to respectively take effect feasible micro public welfare communication strategies? All the above issues will get preliminary analysis and discussion in this paper.

\section{Literature Review}

Professor Shi Zengzhi and Professor Hu Yong from School of Journalism and Communication in Peking University, in their book "New Media Empowerment and the Rise of the Internet of Meanings", from the perspective of new media empowerment and public communication, pose that, micro public welfare enables the public to be suffused with the sense of mission in the society under the visual threshold of new media empowerment. They stress the subject consciousness of an individual in the society and point out that public welfare should be routinized and normalized. Public welfare is not merely the right of a government, an enterprise and rich and powerful people, but is 
also a form of practice in civil autonomy. Changing from depending on government to depending on self, micro public welfare fulfills popularization of public welfare in the whole society. In the meantime, Professor Shi Zengzhi and Professor Hu Yong point out in the fifth chapter of the above book, namely, "Return to the Homeland of an Individual Life That Is Abundant in Ecological Discourse: Community of Destiny and Public Autonomy of the Micro Public Welfare Era", practice of micro public welfare makes it possible for the society to focus on public interest and micro public welfare realizes construction of public good in practice of individual autonomy. Furthermore, they also emphasize that, individual practice in micro public welfare should not only be analyzed in terms of social structure and social functions, but should also interpret the significance of civil actions in micro public welfare based on the community of destiny in terms of recognition of individual identity, values and interests in micro public welfare projects.

On the basis of research by Professor Shi Zengzhi and Professor Hu Yong who pose that normalization of micro public welfare, in essence, is return to the homeland of an individual life that is abundant in ecological discourse, we need to make a brand-new survey on how this individual autonomy practice realizes construction of public good by means of research on group mobilization. Liu, Chaoyang, Lu, Heqiu, Wu, Lian et al make extension of empirical study on the above issue. They put forward three types of mobilization patterns according to different content levels of micro public welfare communication, namely, in-group mobilization, cross-group mobilization and super-group mobilization. Furthermore, they apply social network analysis method and prove the features of in-group mobilization that a team of public welfare is the center and "a small team guides a large group"; they use the framework analysis method and discover that the attribution framework and problem solving framework of mobilization discourse in cross-group mobilization have obvious effects respectively in generating anger and cultivating trust; they prove that in terms of super-group mobilization, it is hard for a team of public welfare to attain an ideal effect by merely virtue of speeches, and it needs to obtain a perfect news role of media attribute in terms of agenda.

However, David A. Snow et al. in their thesis research "Social Networks and Social Movements: A Microstructural Approach to Differential Recruitment" make an empirical study on the critical mobilizing effect of human network and organizations on collective behaviors. The influence of human network on the group of people who personally participate in activities is far greater than appeal from the public occasion, the mass media and e-mails. By contrast, as for the group of people who show sympathy with the activities but fail to participate, the primary factor which makes them give up the participation is that "we have no idea that the people around have participated".

Associate Professor Huang Lu from School of Journalism and Communication in Guangxi Teachers Education University deconstruct the three aspects of communication mechanism in micro public welfare activities in "Study on Public Welfare Communication Based on MicroBlog Platform", namely, diversity of subject, content of communication and process of communication. She indicates that micro public welfare is replacing former single subject public welfare model that is guided by government or enterprise and subjects partaking in micro public welfare are gradually diversified. The multi-subjects including the public, enterprises, public welfare organizations and governmental sectors are interacting to promote development of public welfare. In terms of content of communication, she points out that, in essence, micro public welfare activities are a type of information communication aiming to search for collective assistance for the vulnerable group in the society. Content of communication mainly covers the following several aspects. The first is information about relief which refers to information of forwarded or original public welfare demand. The second is ongoing of public welfare activities, which is to display progress of activities in the form of on-the-spot broadcasting and real time recording. The third is particulars of donation accounts, which is to disclose to the public in time donations and disbursement. The fourth is acknowledgement to donators. Information of microblog public welfare that is forwarded in large quantities is mainly purely help information and most has such characters as "request for forwarding" and "request for spreading", etc. In the process of communication, Associate Professor Huang Lu states clearly that opinion leaders play a crucial role in propelling a topic for discussion in the process of microblog public welfare communication. The opinion leaders spread topics concerning public welfare that are original or that are forwarded to the huge amount of fan bases who then forward or comment on these topics of public welfare and further spread these topics to each group which concentrates on the fans themselves. This kind of nuclear fission communication process helps to expand the communication influence of the topics concerning public welfare.

This paper begins with the perspective of social network relationship to analyze the roles played respectively by information bridge node, core node and long tail node of social network relationship in communication network of micro public welfare information. Then, the paper studies how such multi-subjects as media professionals, public welfare organizations and individuals collaborate to promote communication of micro public welfare and construct 
mutually trustful organizational mechanism. Furthermore, the paper makes an analysis of the communication strategies of multi-subjects for micro public welfare in social network relationship including media professionals, public welfare organizations and microblog individuals in communities of network public welfare.

\section{An Analysis of the Dynamic Role of Multi-subjects as a Node on Internet of Micro Public Welfare Communication from the Perspective of Social Network Relationship}

Just as Professor Peng Lan from School of Journalism and Communication in Renmin University of China points out in her thesis "An Analysis of Information Communication Mechanism in Micro Blog" that the dissemination mechanism of information published by MicroBlog network of public welfare communication based on "node" depends on the "social network" (Note 1) of human kind. Information assembly effect generated by public welfare activities resorting to MicroBlog platform and establishment of a brand of micro public welfare as well as formation of mutual trust of communities in network public welfare organization all are closely connected with "nodes" that play different roles in social network relationship. In a social network relationship, either an individual or a small group is likely to be a "node" in the network. Boosting and mutual correlation of "nodes" weaves the entire micro public welfare communication network. According to the location of an individual or a group and the social capital he possesses as well as his influential power, micro public welfare information communication modes can be classified into information bridge node, core node and long tail node. Among the three kinds of nodes, information bridge node plays a role in connecting "weak ties" of different groups. At the initial stage of "Love Save Pneumoconiosis", the "micro blog queen" Yao Chen acts as an information bridge node. Before Yao Chen forwarded the micro blog "Love Save Pneumoconiosis", the micro public welfare communication circle was still a social relationship network of strong ties in which information content production and communication was still confined to the circle of a small group. However, after Yao Chen who played a role in information bridge node forwarded the micro blog, she has connected different circles of small groups owing to the powerful social capital and influencing power in the social network relationship possessed by public figures and the identity of a celebrity. She disseminated information between the circle of small groups and other micro blog users. This promptly pushed Wang Keqin and his "Love Save Pneumoconiosis" to a commanding height of public opinions. Announcement of topics of public opinions on-line triggered attention of the public on micro public welfare who then participated in projects of micro public welfare. Nevertheless, the duration of time is limited to resort to micro blog platform to trigger focus of micro blog citizens on hot topics about micro public welfare. In order to ensure heat of focus on micro public welfare and push micro public welfare towards communication in an in-depth direction, it is necessary to rely on the collection effect of a long tail node. As what is called "forwarding is power, communication is to rescue and on-looking changes China", it is likely to form influential power of public opinions that suffices to change the society by means of forwarding by micro blog users and by means of participation by all the people and on-line mutual assistance. At the second anniversary of "Love Save Pneumoconiosis" on June 15, 2013, the activity was launched that "one Yuan saves a life for an hour". Just as an old saying goes, "The sand accumulates to form a pagoda -- many littles make a mickle", the "micro" action of donations with small amount by on-line microblog citizens can also be gathered to create tremendous communication value. In the micro public welfare project of "Love Save Pneumoconiosis", long tail nodes consisting of a multitude of MicroBlog citizens get access to the original information released on core modes by virtue of information bridge nodes. Forwarding by long tail nodes through micro blog platform and triggering force of much-talked-about topics together form online information communication network. Long tail nodes reach online consensus by means of mobilization of all the people, participation of small amount, self-management and self-choosing of the life style" in the activity of "one Yuan saves a life for an hour". Such unlimited individual power of long tail nodes facilitates public welfare towards in-depth development by means of forwarding and spreading and amplification of information on micro blog platform.

\section{An Analysis of Communication Strategies of Multi-subjects in Micro Public Welfare Embedded in Social Network Relationship}

On the basis of analyzing and studying behaviors of main market players (including individuals and organizations) and the mutual embeddedness relationship in the social network, the scholar Granovetter ever points out "an actor is neither one that travels outside a social context as an independent atom, nor one that is attached to a role endowed by the social category he belongs to as a slave. Their purposive action attempt is, as a matter of fact, embedded in a real social relationship system that is in operation." (Note 2) Based on the embeddedness theory of Granovetter and the social interpersonal interaction and organizational communication process depending on media reform and media 
transition, the multi-subjects of media professionals, media, celebrities, official authorities, individuals and NGO, etc. which are embedded in social structure and social relationship network play their respective roles in micro public welfare. Moreover, the on-line and off-line interpersonal interaction influences the behavioral orientation of other social subjects. In the following, the paper will make an analysis and initial discussion on how these multi-subjects carry out micro public welfare communication strategies within the framework of social network relationship.

4.1 Media Professionals: Assistance of Social Capital in Information Dissemination and Resource Collection of Micro Public Welfare

The well-known scholar Granovetter ever poses "Either system or morality is likely to successfully avoid opportunistic behavior; operation of a society is impossible without relations between social subjects; a relationship produces mutual trust which, in turn, plays a significance role in trouble-free operation of a society." (Note 2) It is exactly the public trust and powerful social capital that are used by the media and media professionals who possess authority and public trust to boost topics of public welfare and to push public welfare communication to develop in an in-depth direction. To a large extent, all the following are attributed to the fact that media professionals use their powerful social capital, resource advantages and social relationship network for multiple channel resource integration: such micro public welfare projects as "free lunch", "medical insurance for major illnesses" and "Love Save Pneumoconiosis" become topics of focus by a multitude of people; pressure from on-line public opinions finally mobilize a large number of people to partake and gain great support from the government, which also exert some influences upon public policies of the government. Microblog off-line media professionals can make use of their resource advantages to report to various parts on the layout of traditional media. Media journalists can use their occupational resource advantages and the occupational "strong ties circle" based on emotional connection and mutual trust to facilitate information dissemination of micro public welfare projects and collection of resources strength from all parties of the society.

In addition, the occupational experiences which media professionals have accumulated over a long time and their powerful social capital provide convenient conditions for media professionals in operation of topics for micro public welfare projects and help topics for micro public welfare to stand out in the "ocean of topics". Finally, collection of public opinions is formed online and "policy agenda" is catalyzed, which, together, realize the resultant effect of public welfare communication. For instance, Deng Fei puts forward the slogan of "donating 3 Yuan each day for school children in poverty-stricken areas and providing them with free lunch"; Wang Keqin puts forward the slogan of "saving one if we could and offering a little help as we can". These slogans indicate that media professionals have exactly seized the idea of "public welfare by all citizens and by each one" of micro public welfare in setting and operation of topics for public welfare and the civil spirit of self-choice, self-management and self-action of micro public welfare under new media empowerment as well as the urgent cry of focus on social public interest by the public triggered by "micro narration" in daily life. What's more, media professionals may stimulate emotional resonance of the public by virtue of front line investigation, visit, rescue, "oral narration of personal experience by volunteers", and "portrait of life by the parties concerned in rescue" which are imbued with infection and are news narrative techniques used by traditional media. Besides, the media professionals may, at the same time, apply MicroBlog interaction, WeChat access, framework of official website, TaoBao store and Alipay which are new media platforms for in-depth propelling of topics for micro public welfare.

Senior media professionals are likely to play the role of "transfer station" for social information resources in programs of micro public welfare. In organizing and planning micro public welfare programs, senior media professionals represented by Deng Fei and Wang Keqin skillfully utilize their role as media authorities in practice of public relations of micro public welfare programs. They take strict control over major events, take overall consideration of all information and rationally mobilize and allocate social resources in all areas. We here take as an example the micro public welfare program of "medical insurance for major illnesses" that is initiated by Deng Fei and public figures for public welfare, including, Angels investor Xue Manzi, Shui Pi - the Editor in Chief of "China Times" and China Charities Aid Foundation for Children. As a senior media professional, in addition to recruiting volunteers to design the website and set up information resource library, Deng Fei also mobilizes the medical circle, the media circle and the business circle to give counsel on programs of micro public welfare and collects manpower, material resources and financial resources through cross-border cooperation. In the meantime, in the process of planning and running programs of micro public welfare, he also attracts a multitude of artists and noted social public figures to donate collectibles for the programs and to support both on-line and off-line activities auctioned for charity. (Note 3) The national ministries and commissions also release documents in due course, expressing their willingness to make an attempt to bring in commercial insurance for severe illness aids. In this way, resources for the micro public welfare program "medical insurance for major illnesses" may have more possible source channels. Thus, it 
can be seen that, in the process of propelling programs of micro public welfare, the media professionals and the team power of media authorities collected by representatives of media professionals become the "transfer station" in integrating and disseminating information and resources from all fields of the society. In this process, resource allocation is continuously optimized and interests of all participating parties within public welfare organizations are maximized. In addition, in online activities of socialized media, such as, MicroBlog, opinion leaders represented by Deng Fei resort to their identity as media elites and use resources of their media peers and other social circles and construct a cross-border bridge for topics of micro public welfare by means of forwarding in the group of opinion leaders and communicating in the group of multi-level social relationship network. As a bellwether in communication in the group of opinion leaders, the opinion leaders build a "topic landscape" for micro public welfare and continue to provide information and viewpoints concerning public welfare programs to propel in-depth development of public welfare programs. For example, the first hot wave of attention to the micro public welfare program of "Love Save Pneumoconiosis" originated from forwarding by the "MicroBlog queen" Yao Chen. Her "forwarding is to rescue and spreading is to popularize" called for MicroBlog users to focus on and offer help with pneumoconiosis in "Love Save Pneumoconiosis". Afterwards, some celebrities from the cultural circle and entertainment industry, including Xu Xiaoping and Wang Baoqiang, followed up in forwarding. This realized the guiding effect on public opinions by communication of the opinion leaders group and penetrated into practice of public welfare communication by MicroBlog citizens through "information transfer" of online opinion leaders.

\subsection{Public Welfare Organizations: Information Resource Integration Platform Promoting In-depth Development of} Micro Public Welfare Projects

Fragmentization of MicroBlog information is unlikely to disseminate information in a complete and long-acting way, so it is necessary to build a longitudinal and institutional information resource integration platform for micro public welfare programs that will help participants of micro public welfare programs to sustain their focus on the programs and keep contact with the programs after they have contributed their personal resources. This will enhance transparency and reliability of operation of micro public welfare programs. The longitudinal information resource integration platform for micro public welfare programs has two gradients. At the front line is MicroBlog that can release information at real time. The backbone element is bloggers who display content of micro public welfare in details in the forms of graphic video. The backup force of the entire micro public welfare program is the official website of public welfare organizations. As a window to disclose to the public the content of information integration and usage of donations, the official website constantly updates the latest management and operation situation of micro public welfare. This will effectively increase viscosity between donators and programs of micro public welfare. The official website builds trust-oriented network public welfare communities by means of dynamic contact between online Microblog citizens and "viscosity" between Microblog citizens and programs of micro public welfare and set up highly effective and transparent micro public welfare program management and operation mechanism.

\subsection{Group Mobilization in Communities of Micro Public Welfare Network: On-line Consensus and Off-line Action}

Micro public welfare embodies pursuit of goodness by MicroBlog citizens and their common sense of routinization of public interests. "Micro assistance" provided by MicroBlog citizens out of their inward sympathy and mutual trust to the vulnerable groups in the society within their power and mobilization of social network relationship resources of online micro public welfare network community are resistance to strive for "identification" for rights and interests of the vulnerable groups in the society. (Note 4) Identification popularization triggered by concept mobilization in micro public welfare network community can bring about collective behaviors within a larger scope and more public opinion field power in the public space of network. Based on mutual trust between MicroBlog citizens and consensus of micro public welfare network community to public interests, not only will they impose certain pressure upon public policies of government in terms of topics for public welfare, but also they will turn to organized civil public welfare actions off-line in a positive tread out of the sense of social responsibility by citizens for social micro public welfare even though problems of micro public welfare are resolved. Just as Arendt poses that "authority is power that springs forth from the people who act together", micro public welfare community reaches consensus on-line and forms organized collective actions and fulfills authority through the collected power of group mobilization. For example, "the double flash motorcade of July 21 " was not dismissed after the motorcade offered relief in the extraordinary rainstorm in July 21 in Beijing. Instead, they established "a double flash volunteer public service organization" and continued to exercise their mission. (Note 5) Members from micro public welfare community resort to the socialized media platform, such as MicroBlog, to spontaneously interact and correlate with other "long tail nodes" ("power of MicroBlog citizens") in the social network relationship. To the end of public interests and social goodness, they gather together participants of micro public welfare in the weak ties network, which generates the motivation to the career of public welfare. 


\section{Concluding Remarks}

In information communication network of micro public welfare, the multi-subjects (including media professionals, public welfare organizations and MicroBlog citizen individuals in the network community of public welfare) use respectively their own social capital and social network relationship for information and resources integration and boost and evolve micro public welfare into "assembled public welfare". Both online and offline resources are inclined gradually to integration and collection of online resources can trigger organized offline citizen action. Nevertheless, it is the direction of research and discussion in the future how online group mobilization mechanism of micro public welfare and how group resource integration mechanism in the social network relationship will evolve.

\section{References}

David, A. S., Loise, A. Z., Jr., \& Sheldon, E-O. (1980). Social Networks and Social Movements: A Microstructural Approach to Differential Recruitment. American Sociological Review, 45(5), 787-801.

Huang, L. (2013). Study on Public Welfare Communication Based on MicroBlog Platform. Guangxi Social Sciences, (12).

Mark Granovetter. (2007). Embeddedness: Social Network and Economic Action, translated by Luo, Jiade. Beijing: Social Sciences Academic Press.

Peng, L. (2011). An Analysis of Information Communication Mechanism in Micro Blog (4th ed.). Chinese Computer-Mediated Communication Studies. Hangzhou: Zhejiang University Press.

Shen, Y., Liu, C., Lu, H., \& Wu, L. (2013). Study on Mobilization Model of Micro Public Welfare Communication. Journalism and Communication Studies, (3).

Shi, Zengzhi, Hu, Yong, et al. (2013). Return to the Homeland of an Individual Life That Is Abundant in Ecological Discourse: Community of Destiny and Public Autonomy of the Micro Public Welfare Era. New Media Empowerment and the Rise of the Internet of Meanings.

\section{Notes}

Note 1. Peng, Lan. An Analysis of Information Communication Mechanism in Micro Blog (4th ed.). Chinese Computer-Mediated Communication Studies. Hangzhou: Zhejiang University Press, 2011, pp.172-183.

Note 2. Mark Granovetter. Embeddedness: Social Network and Economic Action, translated by Luo, Jiade. Beijing: Social Sciences Academic Press, 2007.

Note 3. Zhang, Mulan. Whether medical insurance for major illnesses can duplicate "free lunch pattern" arouses attention and financing of enterprises needs to be reinforced. Community Times, 2012-07-24, (09).

Note 4. Huang, Yueqin. Politics of Recognition and Order of Discourse in Social Movement: Interpretation on Media Text of the Event of "Strolling" Which Occurred in Xiamen. Communication \& Society (Hong Kong), 2012, Vol. 20, pp.79-114.

Note 5. Shi, Zengzhi, Hu, Yong, et al. Return to the Homeland of an Individual Life That Is Abundant in Ecological Discourse: Community of Destiny and Public Autonomy of the Micro Public Welfare Era. New Media Empowerment and the Rise of the Internet of Meanings, p.69. 